\title{
Information literacy in the Information Age
}

\author{
What I learned on sabbatical
}

by Topsy N. Smalley

$\mathbf{P}$

eople generally acknowledge that the onslaught of the Information Age has had a major impact on how things get done in the world of work. A sabbatical leave during spring semester 2000 enabled me to explore this in some depth.

My objectives were to assess the information literacy needs of different types of workers, gather data from job sites, and develop new instructional module prototypes for our information literacy program, incorporating what I had learned.

Once into the project, additional interests emerged. I discovered it would help to know more about what the high schools were doing in relation to information literacy. And, since my college is a lower-division institution, I wanted to learn what levels of information literacy skills are expected of students at the junior/senior level in four-year institutions.

\section{Gathering information}

Initially, various resource people at my college (e.g., the director of Tech Prep, the dean of Instruction for Career Education, and the Business Division chair) helped arrange contacts with local businesses and organizations. I conducted interviews and observed a variety of workplace situations; talked with upper-division juniors and seniors at four-year schools; hung out in chatrooms with college students, human resources folks, and people in a variety of occupations (e.g., dental hygienists and nurses, since those are two occupational programs associated with my college); posted questions on general and specialized Internet bulletin boards; and read a lot.

To bring it down to a more personal level and make the learning more real, I went to a local temporary employment agency and got a job as a file clerk at a fairly large local company (650 employees). ${ }^{1}$ The job added an important dimension, as I could closely observe the information skills expected of workers during ordinary work cycles.

At the job, I helped out with pre-employment testing, processed résumés and paperwork for one of the company's recruiters, photocopied for the people who did manager training, assembled materials in notebooks for employee orientations, and, of course, tended to the stacks of filing (this was not a paperless company).

Through all of this (and from my other interviews and job observations), I developed a sense about such things as how and why people get rewarded (e.g., bonuses, raises, and comments in performance appraisals); how what you learn contributes to what you get paid; and how workers use search engines and other Internet tools to find out what they need to know. 


\section{Workplaces want good learners; it's what you know, or can learn to do, that is valuable to the organization.}

\section{Other findings}

I came to realize that

1) Workplaces want good learners; it's what you know, or can learn to do, that is valuable to the organization.

2) Employees are knowledge workers. As one worker e-mailed me: "At the organizational level, companies have to start extracting and managing vast amounts of information. Knowledge is a hot commodity. Companies-but, actually, that means the employees-have to know how to put knowledge to work. At my company, they are beginning to refer to what the employees know as the company's knowledge assets."

3) Employees know that they need good information and problem-solving skills. As two workers said:

"We are expected to do research on our own, and to come up with quality, relevant information that we can then use to problem-solve. When people talk about having good information-access skills they aren't just talking theoretical!"

"It's critical in today's world to know how to find and use information, to navigate on the Internet, to use search engines. If you don't have those skills, I think it would be very difficult to even be an entry-level clerk anywhere."

4) In the workplace, and as a junior/senior at a four-year college/university, it is now pretty much assumed you can get around electronically. ${ }^{3}$

5) Management of information resources is critical (as in being able to return to what you were looking at yesterday so you can refer to it in today's meeting and use it tomorrow).

\section{Distributed access to information and what it means}

If you go back to the typical workplace of five or six years ago (i.e., ancient history), information typically flowed up to the top of the organization. The worker bees at the bot- tom of the pyramid may have handled the data as they ran the mainframes, but the information produced was funneled to the management team at the top, where it was used to make decisions.

That's all different now. In many workplaces, each employee has this little box called a computer on his or her desk. The box has many different functions, but one thing is true of all the boxes-they are all connected to the organization's Intranet, and they are all connected to the Internet. Access to information is now distributed.

The very interesting corollary to this is that responsibility for access to needed information resources is now also distributed. The individual worker takes personal responsibility for finding information needed for problem-solving - and is expected to. The unit manager may walk in and say: "By our 10:00 meeting this morning, I want you guys to have been out there on the Internet finding. ..."

\section{What high schools are doing}

Visits to area high schools revealed two major lessons: 1) the California Digital High School project is transforming learning environments and 2) Information Age skills are key components to school technology plans because they are in the schools themselves. There is now an overt emphasis on information literacy and inquiry-based learning. Seniors complete netfolios and other projects that demonstrate their computer and information literacy skills.

My sabbatical experience confirmed that we are living in an increasingly complex, information-laden world and that Information Age skills are critical to success-not only in making a life, but also in making a living. Best of all, I have new "real-world" stories to tell students and a whole bunch of instruction ideas to try out.

\section{Notes}

1. Texas Instruments fabrication plant in Santa Cruz, California

2. Texas Instruments is a pay-for-knowledge (sometimes called pay-for-skills) company that directly rewards employees who increase their skill and knowledge levels. A

(continued on page 704) 
Now the quickest, easiest way to get information on over a quarter-million serials from around the world is even better!

\section{Ulrichsweb.com"}

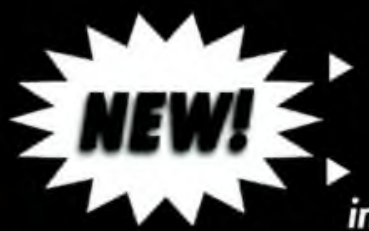

Links to JCR ${ }^{\oplus}$ Web (Impact Factors)

Nine new browse indexes (21 total)

- Quick Search enhancements

- A\&I Hotlinks

- Notify Me function

- Search the Web or selected titles for content using the Northern Light ${ }^{\text {t" }}$ search engine

\section{PLUS}

- Over 26,000 full-text online serials indexed

- Weekly updates

- 70,200 URLs hotlinked

- 69,600 e-mail addresses hotlinked

- Thousands of titles indexed by over 700 A\&I services

- 23,000 refereed, or peer-reviewed serials noted

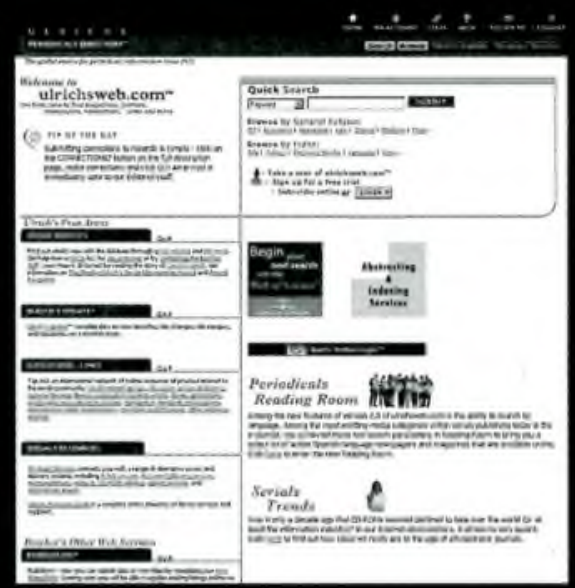

9,400 Reviews from Magazines for Libraries, Library Journal, Mr. Magazine, and others

- Download capability and more...

\section{AND}

Coming soon... links to tables of content and full texts of serials 
journals only. Access: http://ods.od.nih.gov/ databases/ibids.html.

- Consumerlabs. One of the difficulties with herbals is that often the product that you buy may contain very little of the active ingredient. Consumerlabs tests natural products to see what they actually contain; some of their results are available for nonsubscribers. Access: http://consumerlabs.com.

- A Mini-Course in MEDICAL BO'TANY. For those who want to learn about natural products themselves, there is "A Mini-Course in MEDICAL BOTANY" by James A. Duke, one of the gurus on the use of herbals. The site contains his actual lecture notes. Access. http://www.ars-grin.gov/duke/syllabus/

\section{Illegal drugs}

Illegal use of drugs may involve either the use of illegal substances, such as cocaine or heroin, or the illegal use of prescription drugs, such as barbiturates and tranquilizers. Understanding how these drugs act upon the body may help in understanding the addiction.

- National Institute on Drug Abuse. This is a nicely designed site with clearly marked sections for health professionals, parents and teachers, and students. Research reports, statistics, directories of street names for drugs, and a host of other information can be found here. Access: http://www.nida. nih.gov/.

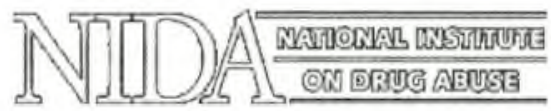

- Drug Enforcement Administration. This Web site contains a listing of "drugs of concern," as well as access to schedules of controlled substances and statistics, such as the number of meth lab seizures over the last decade. Access: http://www.usdoj.gov/ dea/.

- Center for Substance Abuse Research

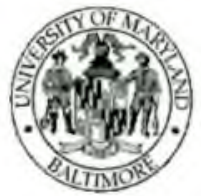
(CESAR). Located at the University of Maryland, the CESAR site provides good basic information and numerous charts and statistics. Access: http:// www.cesar.umd.edu/.

\section{Drug sales statistics}

- Hoover's Online. The pharmaceutical industry is one of the largest in the United States. Information about the industry itself can be found on business sites, such as Hoover's Online. Access: http:// www.hoovers.com.

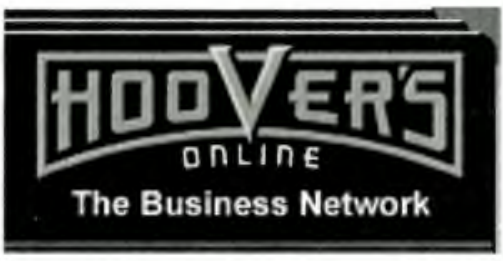

- Drug Topics. Very often students seek statistics on the use or sales of prescription drugs. Once a year, a marketing firm, IMS America, does a National Prescription Audit, sampling the number of prescriptions per drug. Some of its results can be found on the Drug Topics site, a pharmacy trade magazine. Its "Pharmacy Facts and Figures" lists the top 200 brand-name and generic drugs, both by number of prescriptions and by retail sales. Access: http://dt.pdr.net/dt/.

\section{DRUSTOPHaseom THE ONLINE NEWSMA GAZINE FOA PHARMACISTS}

\section{Note}

1. PharmInfonet (pharminfo.com) has been a primary gateway for pharmacy information for a number of years. Unfortunately, it has evidently gone out of existence.

\section{("Information literacy. . ." cont. from page 690)}

major theme that ran through my interviews and other work observations is that it is critical that employees be good learners in any fast-paced work environment.

3. The newly developed TekXam, "the nationwide standard for technical literacy," incorporates many information literacy skills. Note the test objectives and online quiz at their Web site (http://www tekxam. com).

4. "Information Literacy in the Information Age: Sabbatical Project Report," including the instructional modules, is available on the Web at http://www.cabrillo.cc.ca.us/ itsmalley or http://www.topsy.org. 